\title{
LECTINA LIGADORA DA MANOSE: PROPRIEDADES, ISOLAMENTO E PURIFICAÇÃO
}

\section{MANNOSE BINDING LECTIN: FEATURES, ISOLATION AND PURIFICATION}

\author{
PINZON, Raquel P. ${ }^{1}$; ZANIN, Sandra M. W. ${ }^{2}$; MIGUEL, Marilis D. $;$; KLASSEN, G. ${ }^{4}$; \\ BARREIRA, Sandra M. W. ${ }^{5}$
}

1- Farmacêutica (UFPR), Parte do Trabalho de Conclusão de Curso

2- Profa . Adjunta de Farmacotécnica IV, Curso de Farmácia- UFPR

3- Profa . Adjunta de Farmacotécnica III, Curso de Farmácia- UFPR

4- Profa . Associada I do Departamento de Patologia Básica- UFPR

5- Profa . Associada I de Síntese de Fármacos, Curso de Farmácia- UFPR

RECEBIDO: 06/06/08 ACEITO: 27/07/08

\section{RESUMO:}

A lectina ligadora de manose (MBL) é uma proteína encontrada no soro humano, secretada pelo fígado e dependente de cálcio. A MBL é um importante elemento do sistema imune inato, que pode atuar por meio da ativação do sistema do complemento pela via das lectinas e por sua característica de opsonina, facilitando a fagocitose dos patógenos. Esta proteína está associada a doenças infecciosas e auto-imunes, com interferência tanto na susceptibilidade quanto na severidade das patologias. O objetivo deste trabalho foi isolar e purificar a MBL do soro humano, por meio de cromatografia, para uma futura produção de anticorpos monoclonais. O método utilizado para separar e isolar a proteína do pool de soro foi cromatografia por afinidade, realizada em coluna. $O$ protocolo do método foi desenvolvido durante a execução deste trabalho, com base em informações de estudos realizados e publicados anteriormente. Neste estudo, foram utilizadas colunas de diferentes dimensões e a fase estacionária constituiu-se de gel Sepharose 6B-D-manose. As frações obtidas na cromatografia foram submetidas à análise espectrofotométrica, considerando a absorbância como critério de verificação da presença da MBL na amostra. A solução de proteína resultante da separação cromatográfica foi concentrada para permitir a execução da próxima etapa, a identificação por eletroforese. O resultado da eletroforese indicou que a proteína isolada é a MBL. O método cromatográfico desenvolvido neste trabalho mostrou-se eficaz para isolar e purificar a MBL; entretanto, ainda são necessários ajustes para aprimorar o método, a fim de aumentar a rapidez e o rendimento.

Palavras-chave: MBL, lectina, cromatografia, eletroforese, anticorpo.

\begin{abstract}
The mannose-binding lectin (MBL) is a human serum protein, which is secreted by the liver and is calcium-dependent. The MBL is an important constituent of the innate immune system and it may act by activating the complement system through the lectins pathway and by its characteristic of being an opsonin, facilitating the pathogens phagocytosis. This protein is associated to infectious and autoimmune disease, interfering in the individual susceptibility and in the disease severity. The goal of this work was isolating and purifying the MBL from human serum, through a chromatographic method, in order to use it in a future monoclonal antibody production. The method used to isolate and purify the MBL was the affinity chromatography, performed in columns. The method's protocol was developed during the study, based on information from previous published reports. In this study, some columns of different sizes were used and the fixed phase was prepared with Sepharose 6B-D-mannose. The fractions obtained through the chromatography were taken to spectrophotometer analysis, using the absorbance as the determination criteria for the MBL presence in the samples. The protein solution obtained through the chromatography method was concentrated to allow the next step, the eletrophoresis identification. The identification result indicated that the isolated protein is the MBL. The
\end{abstract}


chromatographic method developed during this study showed to be able to isolate and purify the MBL; nevertheless, some adjusts still need to be made to improve the method, in order to enhance its speedy and efficiency.

Keywords: MBL, lectin, chromatography, eletrophoresis, antibody.

\section{INTRODUÇÃO}

A lectina ligadora de manose (MBL) é uma proteína ligadora de carboidrato, presente no soro humano, que participa do sistema imune inato. Essa proteína tem um papel importante na ativação da resposta inflamatória e tem sido associada à patogenesia de doenças infecciosas e auto-imunes (SHARMA et al, 2008).

A MBL é capaz de ativar o sistema do complemento, pela via das lectinas, por meio da formação de um complexo com as serina proteases associadas à MBL, conhecidas como MASPs (JACK; KLEIN; TURNER, 2001). Além disso, a MBL atua também como uma opsonina, ou seja, é capaz de marcar os patógenos para facilitar sua fagocitose (PARHAM, 2001).

A alteração, tanto para mais ou para menos, na concentração sérica de MBL está envolvida com a maior susceptibilidade a determinados tipos de infecções. Existe também uma relação entre a deficiência de MBL e a susceptibilidade a doenças auto-imunes. Ainda, há evidências de que a MBL pode agir como um modulador da severidade das doenças (JACK; KLEIN; TURNER, 2001).

Vários estudos foram realizados com objetivo de isolar a MBL, tanto do soro humano quanto de outros materiais, utilizando principalmente a cromatografia como método de separação e purificação.

O fracionamento de proteínas por meio de cromatografia tem sido praticado desde a década de 1970. A cromatografia por afinidade, utilizada para proteínas, explora as interações entre as proteínas e os ligantes estacionários para realizar a purificação (REGNIER; GOODING, 1992).

Com base nos estudos anteriormente realizados, foi desenvolvido um método para separação, isolamento e purificação da MBL por meio de cromatografia por afinidade em coluna, sendo que a lectina purificada pode ser utilizada para a produção de anticorpos monoclonais.

O interesse pela MBL levou a diversas pesquisas sobre esta proteína, porém, ainda há muitos aspectos a serem estudados. Sua atividade como fator de aumento da fagocitose e sua ação de regulação da severidade das doenças ainda não foram completamente elucidadas, requerendo, assim, que mais estudos sejam realizados. Além disso, ainda não há um método oficial de purificação, o que culmina na necessidade de desenvolvimento de um protocolo que permita a obtenção do maior rendimento de MBL purificada. Por esta razão, o objetivo deste trabalho foi isolar, purificar e identificar a MBL do soro humano, por meio de técnica cromatográfica, para a produção de anticorpos monoclonais.

\section{MATERIAL E MÉTODOS}

\subsection{ETAPAS PRÉ-PURIFICAÇÃO}

\subsubsection{Preparo do gel Sepharose 6B-D-Manose}

A modificação do gel de Sepharose foi executada conforme o procedimento de PORATH, LAAS e JANSON (1975, citado por FORNSTEDT e PORATH, 1975). 
Um volume de $100 \mathrm{~mL}$ de Sepharose $\mathrm{B}$, cuidadosamente lavado com água destilada, foi incubado com $100 \mathrm{~mL}$ de tampão de carbonato $0,5 \mathrm{M}, \mathrm{pH} 11$, e $10 \mathrm{~mL}$ de divinil sulfona. Essa mistura foi mantida em temperatura ambiente por 70 minutos, sob agitação. Em seguida, foi transferida para um copo de Béquer e foi lavada, cuidadosamente, com água destilada.

Para ativar o gel, foram adicionados $100 \mathrm{~mL}$ de uma solução de D-glucose a $20 \%$ (p/v) em tampão carbonato $0,5 \mathrm{M}$, de pH 10. Esta reação de acoplamento foi realizada durante toda uma noite, sob temperatura ambiente.

O produto dessa reação foi extensivamente lavado com água destilada e, então, ressuspendido em um tampão de bicarbonato $0,5 \mathrm{M}$, de $\mathrm{pH} 8,5$. Dois $\mathrm{mL}$ de 2-mercaptoetanol foram adicionados para cada $100 \mathrm{~mL}$ de suspensão. Depois de duas horas, o produto foi recuperado e lavado com água destilada.

\subsubsection{Preparo dos tampões (TERAl et al, 1993)}

O tampão A foi preparado de forma a conter $20 \mathrm{mM}$ de TRIS; 0,15 M de NaCl; 1,0 mM de $\mathrm{CaCl}_{2}$ e $0,05 \%$ de $\mathrm{NaN}_{3} \mathrm{O}$ pH do tampão A foi ajustado para 7,4 com $\mathrm{HCl}$.

O tampão $B$ foi preparado de forma a conter $20 \mathrm{mM}$ de TRIS; $0,15 \mathrm{M}$ de $\mathrm{NaCl} ; 0,01 \mathrm{M}$ de EDTA e $0,05 \%$ de $\mathrm{NaN}_{3}$. O pH do tampão B foi ajustado para $7,4 \mathrm{com} \mathrm{HCl}$.

\subsection{PURIFICAÇÃO DA MBL}

O método da purificação foi adaptado do procedimento descrito por Kawasaki, Kawasaki e Yamashina (1993).

A purificação da MBL foi iniciada com uma mistura de $236 \mathrm{~mL}$ de soro humano congelado. Este soro foi descongelado em temperatura ambiente. Em seguida, procedeu-se à diálise do soro, na temperatura de $4^{\circ} \mathrm{C}$, utilizando a membrana semipermeável e o tampão $A$.

Para a diálise, foi utilizada uma membrana semipermeável que retém moléculas de peso molecular de 12000 ou mais, da Sigma-Aldrich.

Após a diálise, foram recolhidos $425 \mathrm{~mL}$ de solução, que estavam contidos na membrana semipermeável. A este volume, acrescentou-se uma solução de $\mathrm{CaCl}_{2} 1 \mathrm{M}$, até que fosse atingida a concentração de $50 \mathrm{mM}$ de $\mathrm{CaCl}_{2}$.

$\mathrm{O}$ soro com $\mathrm{CaCl}_{2}$ foi aplicado em uma coluna de Sepharose $6 \mathrm{~B}$-manose, com as dimensões de $2,6 \times 13 \mathrm{~cm}$. Esta coluna foi, previamente, equilibrada com o tampão $A$, até que absorbância do eluato, lida em comprimento de onda de $280 \mathrm{~nm}$, fosse menor que $0,02 \mathrm{~cm}^{-1}$.

Retirou-se a proteína da coluna por meio da aplicação do tampão B, em frações de 10 $\mathrm{mL}$, até que se verificasse que a absorbância do eluato fosse menor que $0,02 \mathrm{~cm}^{-1}(\ddot{e}=280$ $\mathrm{nm})$, utilizando-se o tampão B como branco.

Estas frações foram misturadas, homogeneizadas e adicionadas de $\mathrm{CaCl}_{2} 1 \mathrm{~mol} / \mathrm{L}$, até que sua concentração de $\mathrm{CaCl}_{2}$ fosse de $50 \mathrm{mmol} / \mathrm{L}$, para serem aplicadas à segunda coluna. $\mathrm{O}$ volume final obtido foi de $33 \mathrm{~mL}$.

A segunda coluna utilizada foi preenchida com Sepharose 6B-manose, tendo dimensões de $1,0 \times 25 \mathrm{~cm}$. Com finalidade de limpeza do gel, eluiu-se o tampão A nesta coluna, até que a absorbância do eluato, lida em comprimento de onda de $280 \mathrm{~nm}$, fosse menor que $0,02 \mathrm{~cm}^{-}$

1. O branco utilizado foi o tampão $A$.

Os $33 \mathrm{~mL}$ de solução com a proteína $\mathrm{MBL}$, obtidos com a purificação na primeira coluna, já com $50 \mathrm{mmol} / \mathrm{L}$ de $\mathrm{CaCl}_{2}$, foram aplicados à segunda coluna.

Foram obtidas seis frações, que foram levadas ao espectrofotômetro para proceder à leitura da absorbância. O branco utilizado foi o tampão $\mathrm{B}$, adicionado de $\mathrm{CaCl}_{2} 1 \mathrm{~mol} / \mathrm{L}$, até a concentração de $50 \mathrm{mmol} / \mathrm{L}$. 
Fez-se a eluição do tampão $B$ na segunda coluna, com finalidade de retirar a MBL aderida à Sepharose 6B-manose. Foram obtidas doze frações, as quais tiveram suas absorbâncias lidas no espectrofotômetro, com comprimento de onda de $280 \mathrm{~nm}$ e utilizando o tampão B como branco.

Para verificar a presença de proteínas nas frações obtidas pela eluição da solução de proteína na segunda coluna e nas frações obtidas pela eluição do tampão $B$ na segunda coluna, foi realizado um teste qualitativo do biureto.

Todas as frações positivas para o teste qualitativo do biureto foram misturadas e acrescidas de $\mathrm{CaCl}_{2} 1 \mathrm{~mol} / \mathrm{L}$, até que sua concentração fosse de $50 \mathrm{mmol} / \mathrm{L}$.

Esta solução de proteínas foi eluída na terceira coluna, de dimensões $1,0 \times 10 \mathrm{~cm}$, preenchida com Sepharose 6B-manose, com objetivo de ligar a MBL à coluna. Foram obtidas oito frações do eluato cujas absorbâncias foram verificas em comprimento de onda de 280 $\mathrm{nm}$.

Como todos os valores de absorbância obtidos indicaram que ainda havia proteína no eluato, as frações foram eluídas novamente na terceira coluna. As frações obtidas foram submetidas à leitura da absorbância, nas mesmas condições.

Os valores da absorbância continuaram acima de $0,02 \mathrm{~cm}^{-1}$, indicando que a $\mathrm{MBL}$ não aderiu à Sepharose 6B-manose. Assim, aplicou-se o tampão B na terceira coluna, com objetivo de retirar as proteínas possivelmente aderidas à Sepharose modificada. Procedeu-se a leitura da absorbância das frações de tampão B que foi aplicado na coluna (ë = $280 \mathrm{~nm}$ ).

Em seguida, o tampão A foi eluído na terceira coluna, para fins de limpeza. A frações da segunda aplicação da solução de proteínas na terceira coluna e as frações do tampão $B$ eluído na terceira coluna com absorbância maior do que $0,02 \mathrm{~cm}^{-1}$ foram aplicadas novamente à terceira coluna, cada uma separadamente. Fez-se a leitura da absorbância de cada uma das frações, após a passagem pela coluna, com comprimento de onda de $280 \mathrm{~nm}$.

O próximo passo foi retirar qualquer eventual proteína aderida à Sepharose modificada, por meio da eluição do tampão B na coluna. Após a eluição do tampão B, fez-se a leitura da absorbância. As frações com proteína foram adicionadas às demais, obtendo-se um volume de $59 \mathrm{~mL}$ de solução de proteína.

A esta solução foram adicionados $\mathrm{CaCl}_{2} 1 \mathrm{~mol} / \mathrm{L}$ até a concentração de $50 \mathrm{mmol} / \mathrm{L}$, EDTA $40 \mathrm{mmol} / \mathrm{L}$ e Triton-X 0,1\%.

\subsection{CONCENTRAÇÃO DA PROTEÍNA}

A solução de proteína foi concentrada utilizando membrana semipermeável da diálise e polietilenoglicol. A solução foi colocada dentro da membrana e esta foi posta em um copo de Béquer cujo fundo estava forrado com o polietilenoglicol. Por ser mais concentrado que a solução no interior da membrana, o polietilenoglicol retira a água da membrana, enquanto a $M B L$ fica retida.

\subsection{IDENTIFICAÇÃO DA PROTEÍNA}

A amostra de solução de proteína foi submetida à eletroforese em gel SDS-PAGE (dodecil sulfato de sódio) como descrito (LAEMMLI, 1970). Foi preparado um gel separador de poliacrilamida $10 \%$ de $\mathrm{pH} 8,8$, contendo SDS $0,1 \%$ em sistema vertical de eletroforese. Sobre o gel separador foi colocado gel empilhador $0,05 \%$, pH 6,8. A amostra foi fervida 5 minutos antes de aplicação e a eletroforese foi feita em tampão tris $(25 \mathrm{mM})$, glicina $(250 \mathrm{mM})$, SDS $0,1 \%$, pH 8,3. Após a corrida eletroforética, o gel foi corado por 4 horas em $50 \mathrm{~mL}$ de tampão contendo Coomassie Phat gel Blue R, da Pharmacia Biotech. As massas dos marcadores utilizados foram de 97, 66, 45, 30, 20 e 14 kDA. 


\section{RESULTADOS E DISCUSSÃO}

Para a purificação e isolamento da MBL a partir de uma amostra de soro humano, foram realizadas várias etapas de cromatografia em coluna por afinidade. Os eluatos obtidos passaram por análise espectrofotométrica, a fim de verificar se a proteína continuou na amostra eluída ou se aderiu à coluna.

Conforme o resultado obtido, foram definidos os passos seguintes da purificação.

Foram utilizadas três colunas de volumes decrescentes, para permitir a purificação da MBL e a concentração da solução de proteína.

\subsection{RESULTADOS DA SEPARAÇÃO POR CROMATOGRAFIA}

O soro com $\mathrm{CaCl}_{2}$ foi aplicado à primeira coluna, com as dimensões de $2,6 \times 13 \mathrm{~cm}$. A proteína que ficou aderida à coluna foi retirada pela aplicação do Tampão $B$. O tampão $B$ foi recolhido em frações de $10 \mathrm{~mL}$ e estas foram submetidas à análise por espectrofotômetro. $\mathrm{A}$ maior parte da proteína aderida à coluna foi retirada nas frações 6 e 7, recolhendo-se, portanto, as frações de 3 a 8 para proceder ao experimento, que consistiu em aplicar estas frações na segunda coluna.

A segunda coluna passou por um processo de limpeza com o tampão $A$, antes da aplicação das frações 3 a 8 . As amostras de tampão A recolhidas da segunda coluna foram analisadas no espectrofotômetro. Nesta etapa, esperava-se que toda a proteína ficasse retida na coluna. A absorbância das três primeiras frações indicou ausência de proteína nestas amostras, concluindo-se que a MBL ficou aderida à Sepharose modificada. Entretanto, as frações 4, 5 e 6 apresentaram valores de absorbância que indicam a presença de proteína e foram reservadas para a realização do teste do biureto. A etapa seqüencial para este resultado foi retirar a proteína aderida (frações 1,2 e 3) por meio da eluição do tampão B. Com este procedimento foram obtidas 12 frações.

Assim, as frações 1 a 7 e as frações 4, 5 e 6 da etapa de aplicação da solução de proteínas na segunda coluna também foram submetidas ao teste do biureto.

O método do biureto, um dos que se usam para a determinação quantitativa de proteínas (para concentrações finais de proteína entre 0,1 e $2 \mathrm{~g} / \mathrm{L}$ ), tem como base o desenvolvimento de uma cor violeta em solução aquosa resultante da reação da proteína com o reagente mencionado.

As frações de eluato 4, 5 e 6 obtidas após a aplicação da solução de proteínas na segunda coluna e as frações 1, 2, 3 e 4 obtidas por meio da eluição do tampão B na segunda coluna apresentaram resultado positivo para o teste do biureto (essas frações foram misturadas, acrescidas de $\mathrm{CaCl}_{2} 1 \mathrm{~mol} / \mathrm{L}$, até que sua concentração fosse de $50 \mathrm{mmol} / \mathrm{L}$ e eluídas na terceira coluna).

Os resultados esperados para a leitura das absorbâncias dessas frações eram valores abaixo de $0,02 \mathrm{~cm}^{-1}$, que indicariam ausência de proteína no eluato, significando que a MBL ficou retida na coluna. Entretanto, todos os valores de absorbância obtidos indicaram que ainda havia proteína no eluato, ou seja, a coluna não reteve a MBL.

Assim, optou-se por eluir as frações novamente na terceira coluna. Novamente, as frações obtidas foram submetidas à leitura da absorbância, nas mesmas condições. Como os valores da absorbância continuaram acima de $0,02 \mathrm{~cm}^{-1}$, pôde-se concluir que a MBL não aderiu à Sepharose 6B-manose. Este fato pode ser devido a uma saturação da coluna, impedindo-a de reter a proteína. Assim, foi aplicado o tampão B na terceira coluna, com objetivo de retirar as proteínas possivelmente aderidas à Sepharose modificada. As frações obtidas 
foram submetidas à leitura da absorbância em $280 \mathrm{~nm}$. Os resultados indicam que as frações de 1 a 4 contêm proteína (absorbância maior que $0,02 \mathrm{~cm}^{-1}$, em comprimento de onda de 280 $\mathrm{nm}$ ) e que, possivelmente, a coluna estava saturada. A partir da fração 5 , não houve evidência de que a coluna estivesse liberando proteínas, pois as unidades que estavam saturando a coluna provavelmente foram removidas nas frações de 1 a 4 . Assim, esperando-se que a coluna tivesse se tornado apta a ligar a MBL novamente, as frações obtidas na etapa da segunda aplicação da solução de proteínas na terceira coluna e as frações de tampão $B$ contendo proteína obtidas na etapa de eluição deste tampão foram eluídas novamente nesta coluna, uma de cada vez. Somente a fração 1 da etapa de eluição do tampão $B$ na terceira coluna apresentou absorbância menor que $0,02 \mathrm{~cm}^{-1}$, indicando que a MBL não estava mais aderindo à coluna, apesar da limpeza prévia com o tampão B. Assim, concluiu-se que a tentativa de corrigir o problema da saturação da coluna não obteve sucesso e optou-se por proceder ao experimento pela retirada de qualquer eventual proteína aderida à Sepharose modificada. Essa etapa foi realizada por meio da eluição do tampão $B$ e mostrou que apenas as frações 1 e 2 apresentaram absorbância maior do que $0,02 \mathrm{~cm}^{-1}$, sugerindo que somente essas duas frações continham proteína. Essas frações foram adicionadas às demais soluções protéicas (frações 2 a 4 da etapa de eluição do tampão B na terceira coluna e 1 a 8 da etapa da segunda aplicação da solução de proteínas na terceira coluna). O volume resultante dessa solução de proteína foi de $59 \mathrm{~mL}$, a qual foi concentrada utilizando-se polietilenoglicol.

A eletroforese em gel SDS-PAGE indicou que a solução de proteína contém a MBL. Os padrões utilizados foram marcadores com massas de 97, 66, 45, 30, 20 e 14 kDA.

\section{CONCLUSÃO}

A adaptação dos diversos métodos de purificação da MBL descritos na literatura proporcionou o desenvolvimento de uma metodologia possível de ser realizada com os recursos disponíveis no laboratório. Apesar do sucesso na purificação e isolamento da MBL, ainda são necessários ajustes no método, de forma a torná-lo mais rápido e rentável.

\section{REFERÊNCIAS}

FORNSTEDT, N.; PORATH, J. Characterization studies on a new lectin found in Seeds of Vicia ervilia. FEBS Letters, v. 57, n. 2, p. 187-191, 1975.

JACK, D. L.; KLEIN, N. J.; TURNER, M. W. Mannose-binding lectin: targeting the microbial world for attack and opsonophagocytosis. Immunological Reviews, v. 180, n. 1, p. 86-99, 2001.

KAVASAKI, N.; KAWASAKI, T.; YAMASHINA, I. Isolation and characterization of a mannanbinding protein from human serum. The Journal of Biochemistry, v. 94, n. 3, p. 937-947, 1983.

PARHAM, Peter. O Sistema Imune. Porto Alegre: Artmed, 2001.

PORATH, J.; LAAS, T.; JANSON, J.-C. Agar derivatives for chromatography, electrophoresis and gel-bound enzymes. III. Rigid agarose gels cross-linked with divinyl sulphone (dvs). Journal of Chromatography, v. 103, n. 1, 49-62, jan. 1975.

REGNIER, F. E.; GOODING, K. M. Proteins. In: HEFTMANN, E. (Ed.) Chromatography: 
Fundamentals and applications of chromatography and related differential migration methods - Part B: applications. Orinda: Elsevier, Journal of Chromatography Library, v. 51B, p. B151 B168, 1992.

SHARMA, P. et al. Rapid and sensitive detection of autoantibody in rheumatoid arthritis patients by heat-mediated ELISA. Clinical Biochemistry, v. 41, n.1/2, p. 97-102, 2008.

TERAI et al. Human serum mannose binding protein (MBP): development of an enzyme-linked immunosorbent assay (ELISA) and determination of levels in seruim from 1085 normal japanese and in some body fluids. Biochemical Medicine and Metabolic Biology, v. 50, n. 1, p. 111119, 1993. 
Figura 1.

Fluxograma da Purificação e Isolamento da MBL

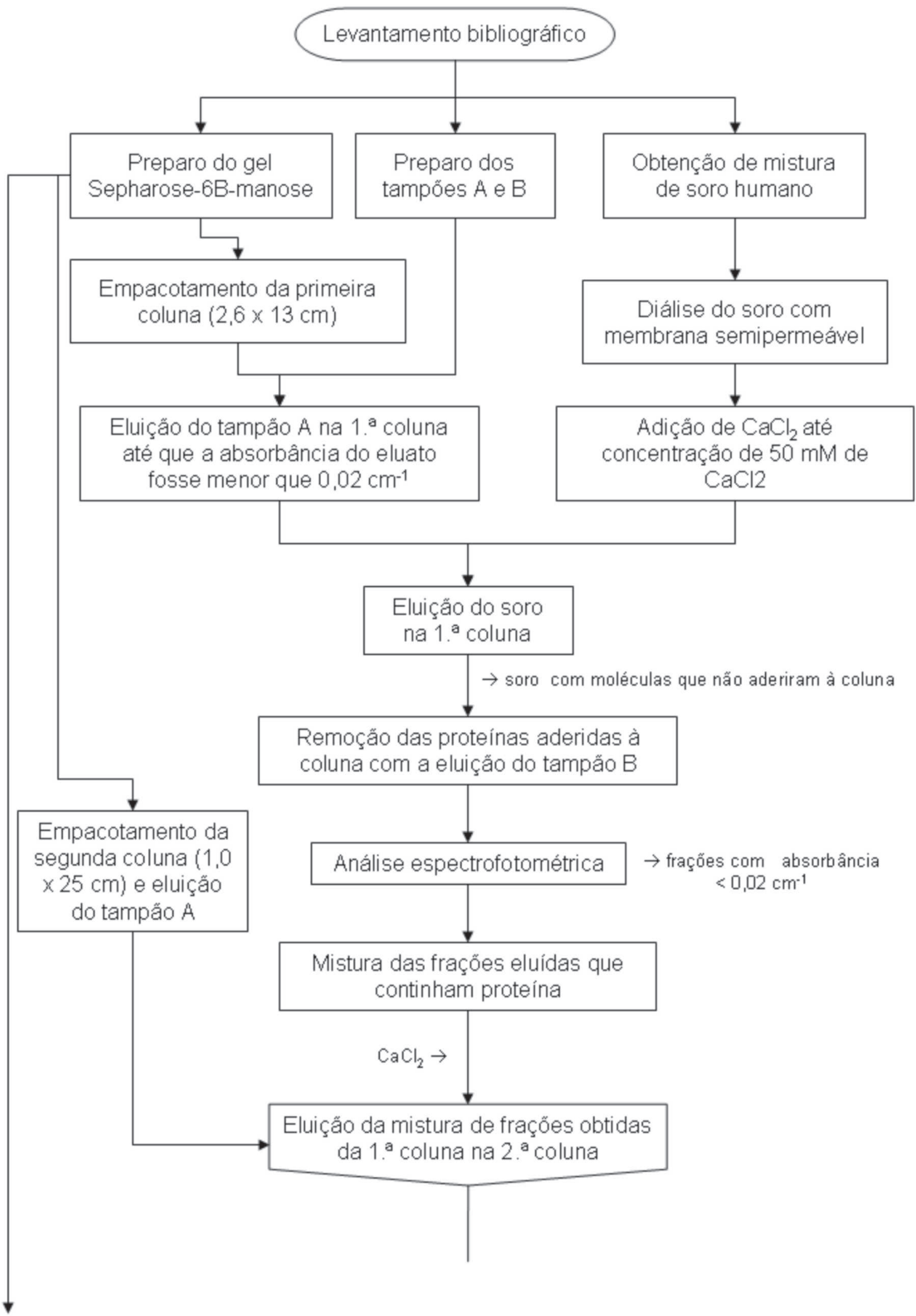




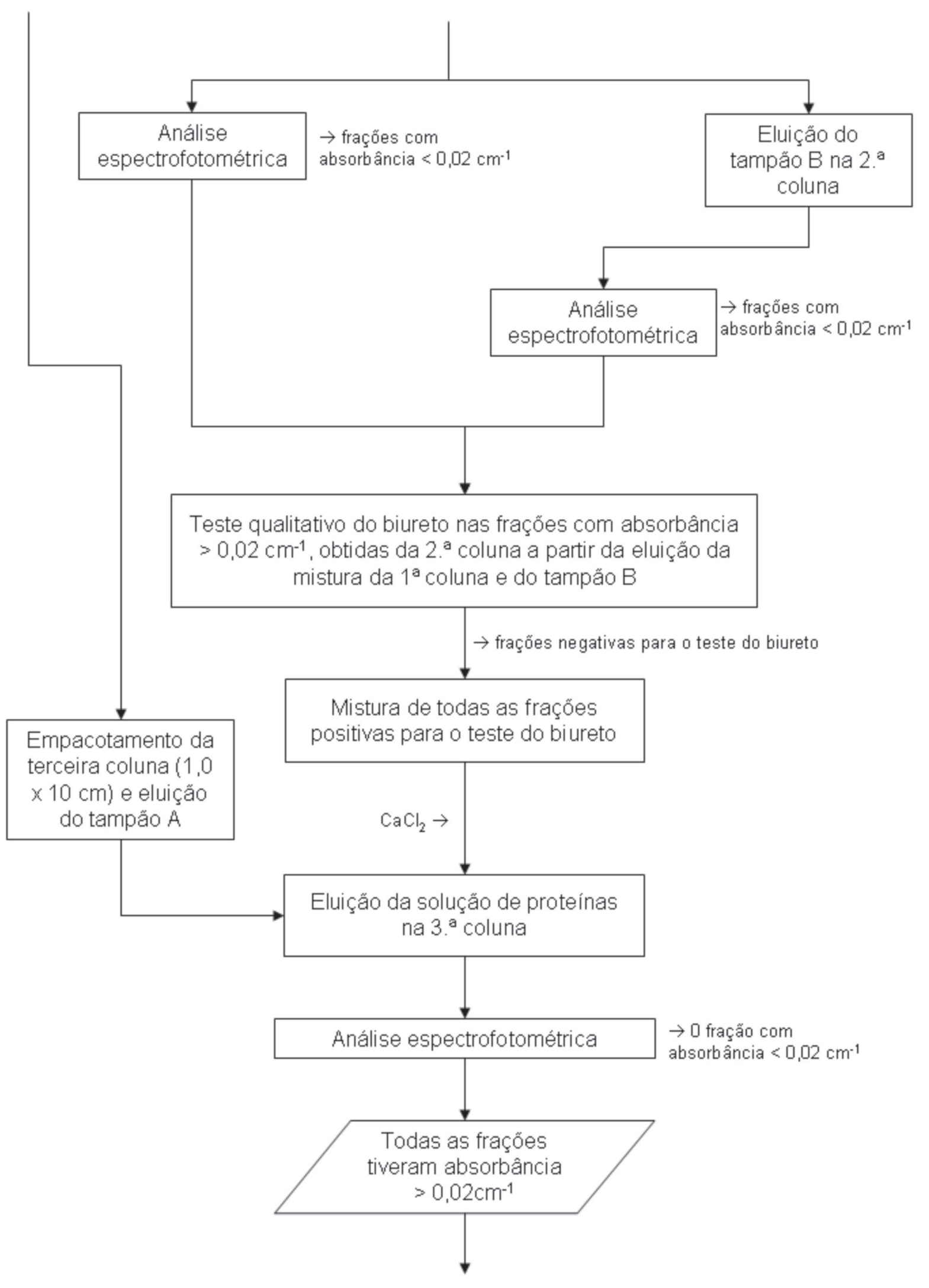




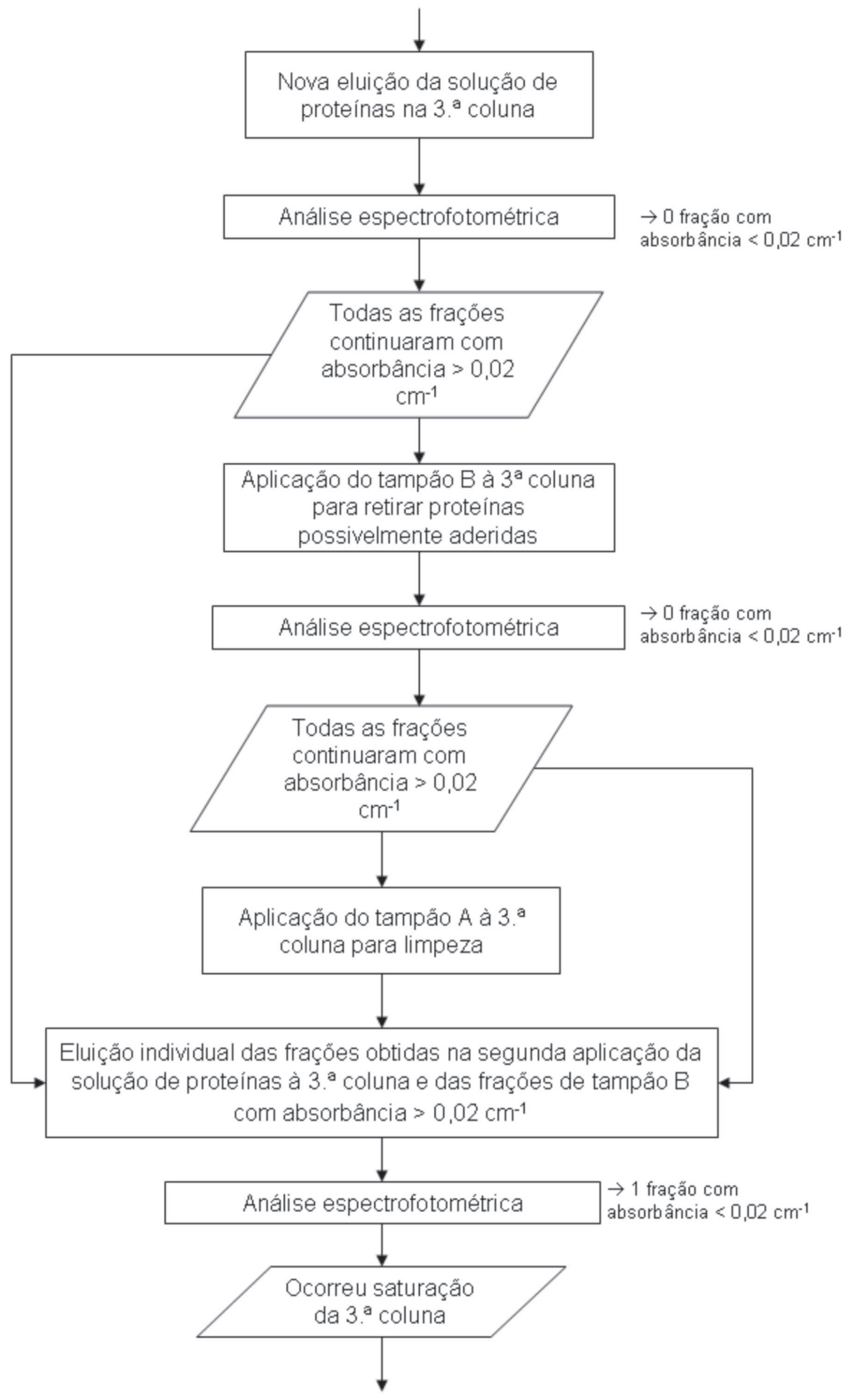




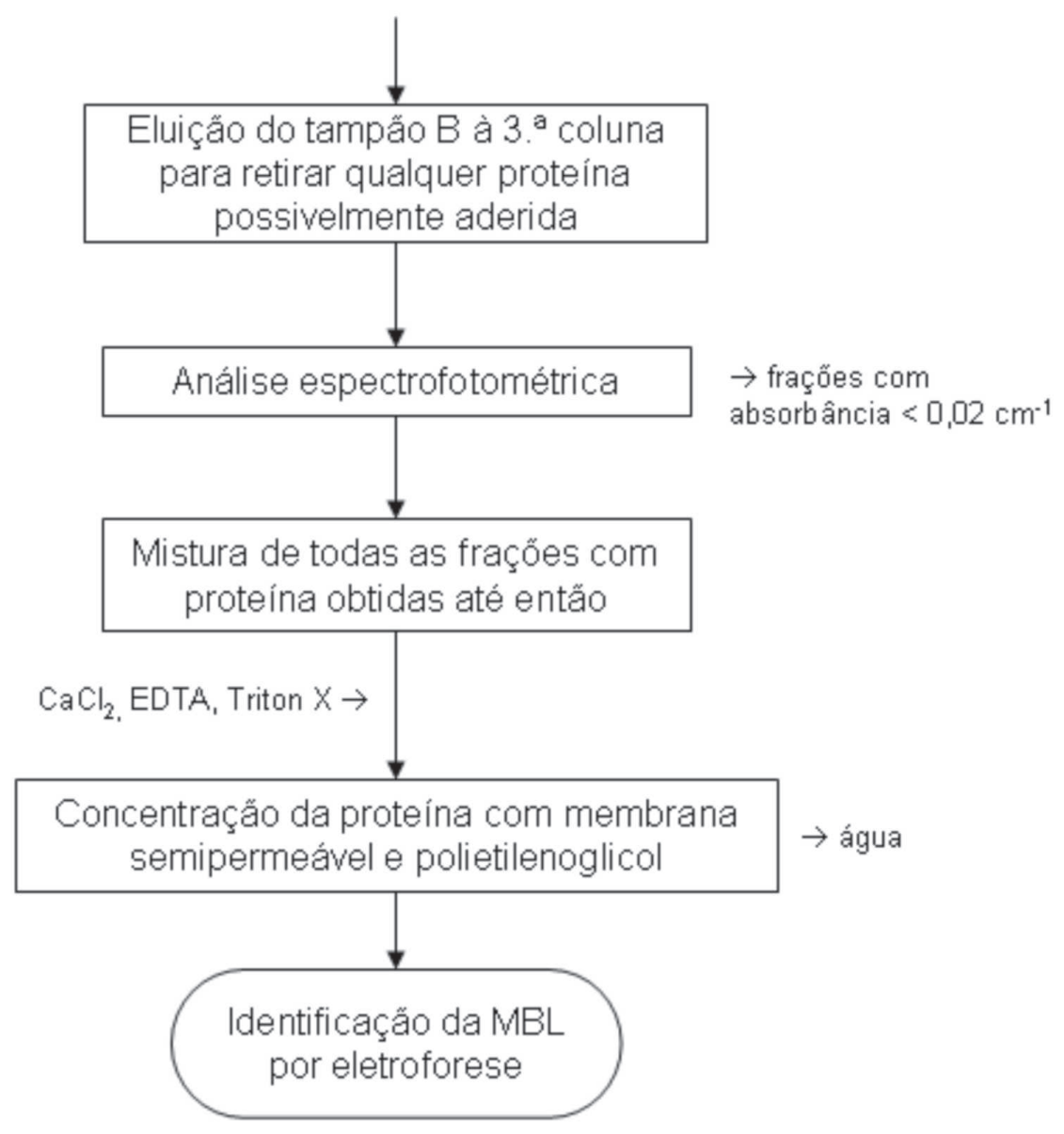

Notas: 1. Todos os procedimentos foram realizados a $4^{\circ} \mathrm{C}$

2. O comprimento de onda na análise espectrofotométrica foi de $280 \mathrm{~nm}$. 